E-ISSN : 2527-712x

Vol.6 (no. 1) Juni 2021

Jurnal Analis Laboratorium Medik

Avalilable Online http://e-journal.sari-mutiara.ac.id/index.php/ALM

DOI: https://doi.org/10.51544/jalm.v6i1.2113

\title{
DETERMINAN YANG BERPENGARUH TERHADAP PEMANTAUAN MUTU EKSTERNAL (PME) BAKTERI TAHAN ASAM (BTA) DI WILAYAH KOTA ADMINISTRASI JAKARTA TIMUR
}

\author{
Aturut Yansen ${ }^{1}$ \\ ${ }^{1}$ Fakultas Sains dan Teknologi, Universitas Binawan \\ Email: aturut.yansen@ binawan.ac.id
}

\begin{abstract}
ABSTRAK
Jakarta Timur belum semua faskes yang melakukan pemeriksaan mikroskopik BTA menurut data tahun 2016 dari total 61 faskes yang melakukan pemeriksaan mikroskopis BTA baru 13 Puskesmas, 16 Rumah Sakit (21\%) yang mengikuti program PME. Dengan hasil 6 faskes mikroskopis yang ikut PME 4 Triwulan dan dari 6 faskes mikroskopis belum ada satupun yang menghasilkan kualitas ujisilang yang baik (0\%). Untuk itu Suku Dinas Kesehatan Jakarta Timur dituntut untuk membina, mengawasi dan mengendalikan fasilitas pelayan kesehatan mikroskopis untuk mampu meningkatkan hasil PME yang baik. Tujuan penelitian ini adalah mempelajari dan menjelaskan determinan yang mempengaruhi hasil PME dari laboratorium yang melaksanakan pemeriksaan Mikroskopis sedian dahak diwilayah Kota Administrasi Jakarta Timur. Metode penelitian yang digunakan adalah Cross Secsional Study Yaitu variabel dependen dan independen diamati pada periode yang sama dan metode yang digunakan adalah metode survey. Analisa data menggunakan uji chi-square dan regression logistic. Dari 60 responden yang diuji ada pendidikan diploma yaitu 62\%, pernah dilatih $<2$ tahun yaitu 95\%, memiliki 2 tenaga yaitu 100\%, menganggarkan tiap tahun yaitu 96\%, sarana dan prasarana yang baik yaitu $79 \%$. Determinan anggaran yang sangat berhubungan dengan pelaksanaan PME BTA yaitu 96\%. Artinya determinan anggaran yang mempunyai hubungan yang sangat signifikan dengan pelaksanaan PME BTA dimana variabel ini memiliki p value kurang dari 0.05 dan memiliki OR 99.24. Kesimpulan dari hasil ini bahwa Suku Dinas Kesehatan Jakarta Timur dapat memastikan semua faskes menganggarkan tiap tahun walaupun sementara ini masih ada bantuan dari luar negeri untuk pelaksanaan PME BTA.
\end{abstract}

Keywords/Kata Kunci :PME BTA, keterampilan, jumlah SDM, standar profesi, anggaran, sarana dan prasarana. 
Aturut Yansen|Determinan Yang Berpengaruh Terhadap Pemantauan Mutu Eksternal (PME) Bakteri Tahan Asam (BTA) Di Wilayah Kota Administrasi Jakarta Timur

\section{PENDAHULUAN}

Indonesia telah menetapkan program PME yang dikelola oleh masing-masing provinsi menggunakan pedoman yang dikembangkan di tingkat nasional. PME terdiri dari uji silang, bimbingan teknis dan tes panel.

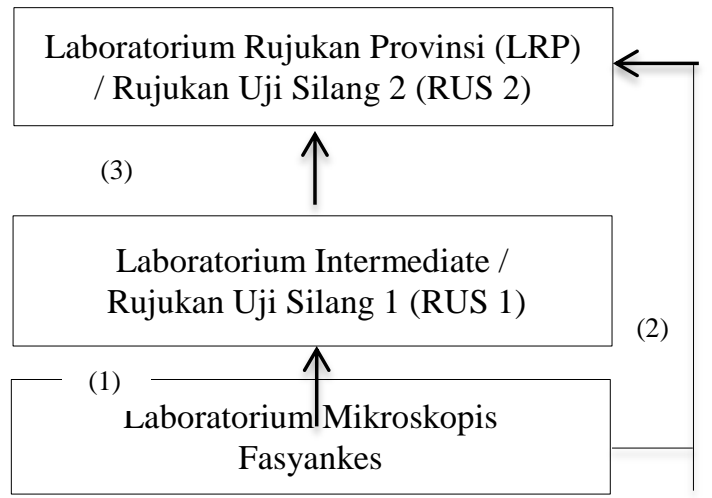

Gambar 1. Alur uji silang Mikroskopis TBC

Keterangan:

1. Uji silang laboratorium mikroskopis fasyankes oleh laboratorium RUS 1

2. Bila tidak ada laboratorium intermediate, uji silang dilakukan oleh LRP. Dalam hal ini LRP berperan sebagai laboratorium RUS 1

3. Bila terjadi ketidaksesuaian (discordance), dilakukan pemeriksaan ulang oleh LRP. Dalam hal ini LRP berperan sebagai laboratorium RUS 2. Bila di provinsi tersebut tidak ada laboratorium RUS 1, maka sediaan discordant dibaca oleh penyelia/supervisor LRP. Kinerja laboratorium mikroskopis TB harus terjaga

Kinerja laboratorium mikroskopis TBC harus terjaga dengan PME yang teratur dan berkesinambungan, yaitu 4 kali per tahun dengan metode Lot Quality Assurance Sampling (LQAS). Dengan meluasnya layanan diagnosis melalui Tes Cepat Molokuler (TCM) maka pemeriksaan mikroskopis hanya akan digunakan untuk pemantauan selama pengobatan sehingga jumlah pemeriksaan mikroskopis akan berkurang. Hal ini akan menyebabkan banyaknya sediaan BTA negatif. Pada metode Lot Quality Assurance Sampling (LQAS), meningkatnya jumlah sediaan BTA negatif dan rendahnya Slide Positivity Rate (SPR) dapat meningkatkan jumlah sediaan yang harus diuji silang. Hal ini berakibat meningkatnya beban kerja laboratorium RUS dan meningkatnya pembiayaan kegiatan PME. Perlu harus direncanakan metode pengambilan uji silang untuk mengantisipasi kondisi tersebut di Fasilitas Pelayanan Kesehatan (fasyankes) yang memiliki alat TCM atau yang berjejaring dengan laboratorium rujukan TCM. Partisipasi uji silang bervariasi antar provinsi. Proporsi cakupan uji silang dari tahun 2013 sampai 2015 berada pada rentang $12-45 \%$, proporsi kinerja baik di antara fasyankes yang mengikuti uji silang $62-81 \%$, dan proporsi kinerja baik di antara seluruh fasilitas pelayanan kesehatan mikroskopis adalah $8-26 \%$.

\section{METODE PENELITIAN}

Jenis penelitian yang digunakan adalah Cross Secsional Study Yaitu variabel dependen dan independen diamati pada periode yang sama dan metode yang digunakan adalah metode survey (Riwidikto,2007)

Data primer untuk variabel bebas dan variabel terikat didapatkan secara bersamaan dengan cara mendatangani dan wawancara responden yang dipilih sebagai sampel, wawancara dilakuakn dengan menggunakan angket (lembar pertanyaan)

\section{HASIL PENELITIAN}

Tabel 5.5 hasil uji Univariat Distribusi data menurut Pendidikan tenaga laboratorium, Keikut sertaan PME, Terakhir dilatih, Tenaga analis yang ada, Anggaran untuk BTA, Sarana Dan Prasarana

\begin{tabular}{|c|c|c|c|}
\hline No. & Variabel & Frekwensi & $\begin{array}{c}\text { Presentase } \\
\%\end{array}$ \\
\hline \multirow[t]{4}{*}{1} & sertaan & & \\
\hline & PME & & \\
\hline & • 4 kali & 28 & 47 \\
\hline & - <4 kali & 32 & 53 \\
\hline \multirow[t]{3}{*}{2} & Pendidikan & & \\
\hline & - SMK & 18 & 30 \\
\hline & - Diploma & 42 & 70 \\
\hline \multirow[t]{4}{*}{3} & Terakhir dilatih & & \\
\hline & - $<2$ tahun & 22 & 37 \\
\hline & - $<5$ tahun & 11 & 18 \\
\hline & $\begin{array}{l}\text { - Belum } \\
\text { pernah }\end{array}$ & 27 & 45 \\
\hline \multirow[t]{3}{*}{4} & Tenaga Analis & & \\
\hline & - 2 orang & 16 & 27 \\
\hline & - $<2$ orang & 44 & 73 \\
\hline \multirow[t]{3}{*}{5} & $\begin{array}{l}\text { Anggaran Untuk } \\
\text { BTA }\end{array}$ & & \\
\hline & $\begin{array}{l}\text { - Dianggarkan } \\
\text { tiap tahun }\end{array}$ & 26 & 43 \\
\hline & $\begin{array}{ll}\text { - } & \text { Tidak } \\
& \text { dianggarkan }\end{array}$ & 34 & 57 \\
\hline \multirow[t]{3}{*}{6} & Sapras & & \\
\hline & - Baik & 33 & 55 \\
\hline & - Kurang & 27 & 45 \\
\hline
\end{tabular}

\section{Universitas Sari Mutiara Indonesia}


Dari tabel 5.5 diketahui bahwa ada $32(53 \%)$ responden yang mengikuti PME BTA <4 kali dalam 1 tahun, masih jauh dari target yang ditetapkan oleh pemerintah. Respponden berpendidikan diploma $42(70 \%)$, responden yang belum pernah dilatih ada $27(45 \%)$, responen yang memliki tenaga analis $<2$ orang $44(73 \%)$, reponden yang tidak menganggarkan ada 34 (57\%), dan responden yang memiliki sarana dan prasarana yang baik $33(55 \%)$

Hasil uji analisa Bivariat :

Tabel 5.6 hasil uji Bivariat Distribusi data menurut Pendidikan, Terakhir dilatih, Tenaga analis yang ada, Anggaran untuk BTA, Sarana Dan Prasarana dalam keikut sertaan PME
Tabel 5.3 Model Pertama Regresi Logistik Ganda Variabel pendidikan, terakhir dilatih, tenaga analis, Anggaran dan Sapras

\begin{tabular}{|l|l|l|l|l|}
\hline No & $\begin{array}{l}\text { Variabel } \\
\text { Independen }\end{array}$ & B & OR & $\begin{array}{l}\text { P } \\
\text { Value }\end{array}$ \\
\hline 1 & Pendidikan & 18.367 & $9.478 \mathrm{E} 7$ & 0.999 \\
2 & $\begin{array}{l}\text { Terakhir } \\
\text { Pelatihan }\end{array}$ & & & \\
& Pelatihan 1 & 0.532 & 1.703 & 0.735 \\
& Pelatihan 2 & 39.264 & $1.127 \mathrm{E} 17$ & 0.999 \\
3 & Tenaga analis & 18.964 & $1.722 \mathrm{E} 8$ & 0.998 \\
4 & Anggaran & 2.705 & 14.960 & 0.055 \\
5 & Sapras & -18.591 & 0.000 & 0.999 \\
\hline
\end{tabular}

Dari tabel 5.3 ada beberapa variabel yang mempunyai nilai $\mathrm{p}$ value $>0.05$, salah satu dari variabel ini harus dikeluarkan. Disini dipilih pendidikan untuk dikeluarkan

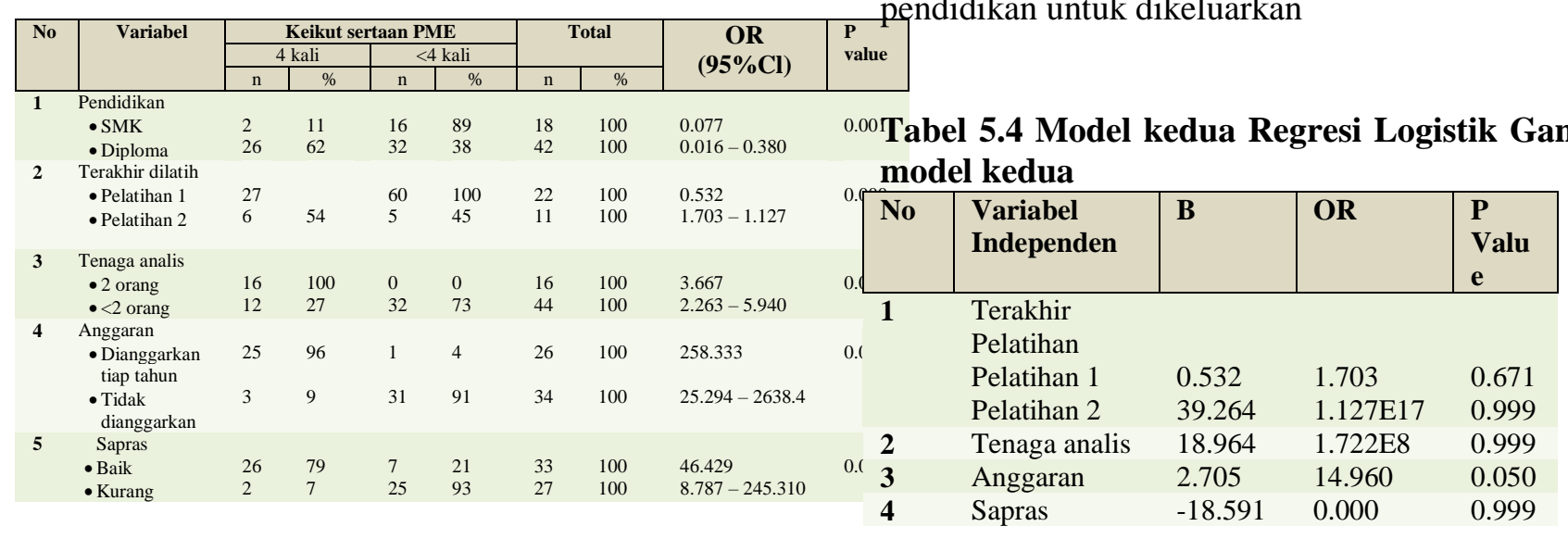

Berdasarkan tabel 5.6 diatas terdapat hubungan yanng sangat signifikan dari semua variabel yang diuji terhadap keikut sertaan PME 4 kali dalam satu tahun, pendidikan $\mathrm{p}$ value $=0.001$, terakir dilatih $\mathrm{p}$ value $=0.000$, tenaga analis $\mathrm{p}$ value $=$ 0.000 , anggaran $\mathrm{p}$ value $=0.000$, sarana dan prasarana $\mathrm{p}$ value $=0.000$

Hasil uji Multivariat :

Model Pertama
Dari tabel 5.4 didapatkan bahwa variabel pelatihan, tenaga analis dan sapras mempunyai $\mathrm{p}$ value > 0.05. selanjutkan dikeluarkan variabel yang paling besar. Dimana disini ada nilai yang sama yaitu pelatihan 2, tenaga analis dan sapras. Untuk itu dipilih salah satu untuk dikeluarkan dari model. Dipilih pelatihan untuk dikeluarkan.

Tabel 5.5 Model kedua Regresi Logistik Ganda model ketiga

\begin{tabular}{|l|l|l|l|l|}
\hline No & $\begin{array}{l}\text { Variabel } \\
\text { Independen }\end{array}$ & $\mathbf{B}$ & OR & $\begin{array}{l}\text { P } \\
\text { Value }\end{array}$ \\
\hline $\mathbf{1}$ & Tenaga analis & 18.964 & $1.722 \mathrm{E} 8$ & 0.999 \\
$\mathbf{2}$ & Anggaran & 2.705 & 14.960 & 0.003 \\
$\mathbf{3}$ & Sapras & -18.591 & 0.000 & 0.144
\end{tabular}

Dari tabel 5.5 didapatkan bahwa variabel tenaga analis dan sapras mempunyai $\mathrm{p}$ value $>0.05$. selanjutkan dikeluarkan variabel yang paling besar. Dimana disini ada nilai yang besar yaitu tenaga analis. Untuk itu dipilih tenaga analis untuk dikeluarkan dari model. 
Aturut Yansen|Determinan Yang Berpengaruh Terhadap Pemantauan Mutu Eksternal (PME) Bakteri Tahan Asam (BTA) Di Wilayah Kota Administrasi Jakarta Timur

Tabel 5.6 Model kedua Regresi Logistik Ganda model terakhir

\begin{tabular}{|l|l|l|l|l|}
\hline No & $\begin{array}{l}\text { Variabel } \\
\text { Independen }\end{array}$ & B & OR & $\begin{array}{l}\text { P } \\
\text { Value }\end{array}$ \\
\hline $\mathbf{1}$ & Anggaran & 4.598 & 99.240 & 0.000 \\
$\mathbf{2}$ & Sapras & 1.831 & 6.240 & 0.144
\end{tabular}

Dari tabel 5.6 didapatkan bahwa variabel anggaran mempunyai $\mathrm{p}$ value $<0.05$. dengan demikian proses pengeluaran variabel telah selesai, dan hasilnya sebagai sebagai berikut

Tabel 5.7 Model kedua Regresi Logistik Ganda model terakhir

\begin{tabular}{|l|l|l|l|l|}
\hline No & $\begin{array}{l}\text { Variabel } \\
\text { Independen }\end{array}$ & $\mathbf{B}$ & OR & $\begin{array}{l}\text { P } \\
\text { Value }\end{array}$ \\
\hline $\mathbf{1}$ & Anggaran & 4.598 & 99.240 & 0.000
\end{tabular}

Hasil akhir analisa multivariat didapat hanya ada satu variabel yang berhubungan signifikan dengan keikut sertaan kegiatan PME BTA yaitu anggaran. Dalam analisa ini anggaran merupakan salah satu determinan yang membuat faskes yang berada diwilayah Kota Administrasi Jakarta Timur tidak mampu mengikuti kegiatan PME BTA 4 kali dalam satu tahun.

\section{KESIMPULAN}

Dari hasil penelitian dan pembahasan tentang determinan yang berpengaruh terhadap Pemantapan Mutu Eksternal (PME) Bakteri Tahan Asam (BTA) di wilayah Kota Administrasi Jakarta Timur, untuk ini peneliti mengabil kesimpulan bahwa :

1. Bahwa pelaksanaan PME sebanyak 4 kali yang wajib diikuti oleh fasilitas pelayana kesehatan yang berada dijakarta timur masih belum berjalan dengan baik seperti yang ditargetkan oleh Kementerian Kesehatan, ini dikarenakan masih banyak kendala - kendala yang dihadapi oleh pelaksanaan laboratorium TBC.

2. Dari semua variabel yang menjadi determinan pelaksanaan PME BTA sebanyak 4 kali semuanya memiliki hubungan yaitu; keterampilan, jumlah SDM, standar profesi, anggaran, sarana dan prasarana.

3. Sedangkan variabel yang sangat dominan dalam penelitian ini adalah variabel anggaran yang membuat pelaksanaan PME BTA dapat berjalan dengan baik yaitu sebanyak 4 kali dalam satu tahun.

\section{DAFTAR PUSTAKA}

Abdul Wahab, Solichin, 1997, Analisis Kebijaksanaan, Dari Formulasi Keimplementasi Kebijaksanaan Negara. Jakarta, Penerbit PT Bumi Aksara

Anggara, Sahya, 2014, Kebijakan Publik, Penerbit CV Pustaka Setia, Bandung.

A.S, Munandar. (2001). Psikologi Industri dan Organisasi. Jakarta : UI

Assauri , Sofyan. 1996, Manajemen Pemasaran Moderen-Dasar, Konsep dan Strategi, Edisi I, PT Raja Grafindo Persada, Jakarta

Dwiyanto, Levine, 1995, Reformasi Tata Pemerintahan Dan Otonomi. Daerah, PSKK-UGM, Yogyakarta.Follet, Mary Parker. (1997). Defenition of Management.

Edi Sutrisno, 2009, Manajemen Sumber Daya Manusia, Jakarta, Kencana Pernada Media Group

Islamy, Irfan, 2001, Prinsip-prinsip Perumusan Kebijakan Negara, Cetakan X, Bumi Aksara, Jakarta.

Jones, Charles O, 1996, Pengantar Kebijakan Publik (PublicPolicy) Terjemahan Ricky Ismanto, PenerbitP.T. Raja Grafindo Persada, Jakarta.

Kemenkes. 2015. buku standar pelayanan laboratorium tuberkulosis.Jakarta. Kemenkes

Kemenkes. 2015. buku Pedoman Nasional Pengendalian Tuberkulosis. Jakarta. Kemenkes

Kamus Besar Bahasa Indonesia, Pusat Bahasa Departemen Pendidikan Nasional, 2014, Cetakan VII, Edisi IV, Penerbit PT Gramedia Pustaka Utama, Jakarta.

M. Nafarin, 2000. Penganggaran Perusahaan. Jakarta: Salemba Empat

Mulyadi, Dedy, 2015, Studi Kebjakan Publik dan Pelayanan Publik, Penerbit Alfabeta, Bandung.

Notoatmodjo, S. 2010. Metodologi Penelitian Kesehatan. Jakarta : Rineka Cipta

Nugroho D, Riant, 2006, Kebijakan Publik Untuk Negara-Negara Berkembang, Penerbit PT Elex MediaKomputindo, Jakarta.

Nurcholis, Hanif, 2007, Teori dan Praktek Pemerintahan dan Otonomi Daerah, Penerbit P.T. Gramedia Widiasarana Indonesia, Jakarta.

Soemarjadi, Muzni Ramanto, Wikdati Zahri. 1991. Pendidikan Keterampi-lan. Jakarta: 
Aturut Yansen|Determinan Yang Berpengaruh Terhadap Pemantauan Mutu Eksternal (PME) Bakteri Tahan Asam (BTA) Di Wilayah Kota Administrasi Jakarta Timur

Depdikbud

Sonny Sumarsono. 2003. Manajemen Koperasi. Graha Ilmu, Yogyakarta. Jogiyanto. 2005

Sudinkes Jaktim. 2016; laporan tahunan TB12. Jakarta. Sudinkes

Sutrisno, Edy (2009), Mengenal Perencanaan, Implementsi \& Evaluasi Kebijakan/Program, Penerbit, Untag Press, Surabaya.

Tahir, Arifin, 2014, Kebijakan Publik \& Transparansi Penyelenggaran Pemerintah Daerah, Penerbit Alfabeta, Bandung.

Welsch, Hilton, Gordon. Anggaran Perencanaan dan Pengendalian Laba Buku 1 (diterjemahkan oleh Purwaningsih dan Maudy Warouw). 2000. Jakarta : Salemba Empat. 